\title{
Coloration of Aromatic Polyimides and Electronic Properties of Their Source Materials
}

\author{
Shinji Ando, ${ }^{*}$ Tohru MatsuUra, and Shigekuni SaSaki \\ NTT Science and Core Technology Laboratory Group, \\ Nippon Telegraph and Telephone Corporation, \\ Midori-cho 3-chome, Musashino-shi, Tokyo 180, Japan
}

(Received July 8, 1996)

\begin{abstract}
The relationships between the color intensities of polyimide films and the electronic properties of their source materials - aromatic diamines and aromatic tetracarboxylic dianhydrides - are discussed. The arrangement of the diamine moieties in order of color intensity of polyimides shows fairly good agreement with the order of the electron-donating properties of the diamines estimated from ${ }^{15} \mathrm{~N}$ NMR chemical shifts $\left(\delta_{\mathrm{N}}\right)$. On the other hand, the arrangement of the dianhydrides moieties in order of color intensity of polyimides agrees with the order of the electron-accepting properties of the dianhydrides estimated from experimental and calculated electron affinity $(E A)$ although systematic inconsistencies are observed for the dianhydrides having $-\mathrm{CF}_{3}$ groups and a benzophenone carbonyl group. These results are consistent with the formation of charge transfer complex (CTC) and indicate that the electron-donating properties of diamines and electron-accepting properties of dianhydrides are retained to a significant extent even in polyimide molecular chains.
\end{abstract}

KEY WORDS Polyimide / Coloration / Charge Transfer Complex / Dianhydride / Diamine / Nuclear Megnetic Resonance Chemical Shift / MNDO-PM3 /

Optical transparency of polyimide films is of special importance in some applications such as flexible solar radiation protectors, ${ }^{1}$ orientation films in liquid crystal display devices, ${ }^{2}$ optical waveguides for communication interconnects, ${ }^{3}$ and optical half-waveplates for planar lightwave circuits. ${ }^{4}$ However, most of the conventional polyimide films always show considerable coloration ranging from pale yellow to deep brown. Rogers ${ }^{5}$ first reported that optically transparent and colorless polyimides can be synthesized from a dianhydride and a diamine that have hexafluoroisopropyridene $\left(-\mathrm{C}_{\left.\left(\mathrm{CF}_{3}\right)_{2}-\right)}\right.$ groups. We have reported that the fluorinated polyimides derived from 2,2'-bis(trifluoromethyl)-4,4'-diaminobiphenyl (TFDB) exhibit excellent properties needed for optical applications. ${ }^{6}$ In particular, the polyimide derived from 2,2-bis(3,4-dicarboxyphenyl)hexafluoropropane dianhydride (6FDA) and TFDB show no color, high transparency in the visible region, and low optical transmission losses in the near-infrared region as well as low dielectric constants, low refractive indices, and low water absorption. The idea that fluorination of dianhydride and diamine moieties give colorless polyimides are widely accepted. On the other hand, we have recently reported the first synthesis of perfluorinated polyimides that have very high optical transparency over the entire range of optical communication wavelengths $(1.0-1.7 \mu \mathrm{m})$ and high glass transition temperatures over $300^{\circ} \mathrm{C}^{7,8}$ Despite the high fluorination of the diamine and dianhydride, the perfluorinated polyimides show considerable coloration ranging from orange to brown. This fact indicates that the fluorination of source materials does not necessarily lead to colorless polyimides. If the coloration of polyimide films can be predicted from the properties of their source materials, it should be helpful for the development of polyimides used for optical applications.
Bikson et al. ${ }^{9}$ showed that the color intensity of polyimides is related to the structure of the monomers from which they are derived. They mentioned that the dianhydride structure is more influential in determining the color intensity of polyimides than the diamine structure, and they attributed this to the extent of conjugation at the 5-membered imide ring. Dine-Hart et al. ${ }^{10}$ proposed the formation of charge transfer complex (CTC) between alternating electron-donor (diamine) and electron-acceptor (dianhydride) moieties. According to the CTC formation theory, ${ }^{11}$ strong electron-donors and strong electron-acceptors stabilize both the ground and the excited state of electrons and reduce the electronic transition energy between occupied and the unoccupied molecular orbitals. Figure 1 illustrates the intra- and inter-molecular CTC formation in polyimides. Applying this theory to the polyimide molecules, the electronic transition energy from the highest occupied molecular orbital (HOMO) located around the imidenitrogen to the lowest unoccupied molecular orbital (LUMO) located around the carbonyl carbons should be determined from the electron-donating property of diamine and the electron-accepting property of dian-

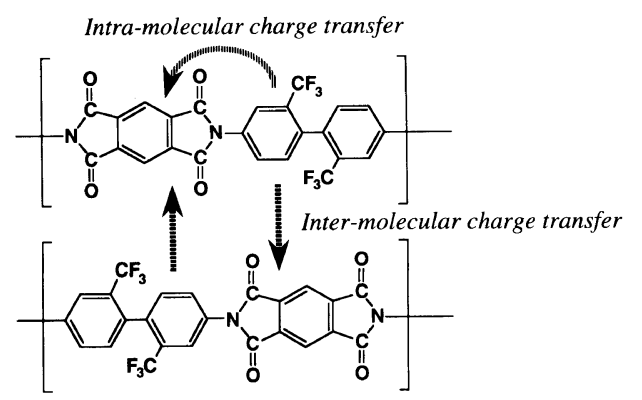

Figure 1. The intra- and inter-molecular charge transfer of polyimides. Arrows indicate the directions of electron transfer.

* Present address: Department of Polymer Chemistry, Tokyo Institute of Technology, Ookayama 2-12-1, Meguro-ku, Tokyo 152, Japan. 
hydride. Kotov et al. ${ }^{12}$ discussed the quantitative color changes in the polyimides derived from pyromellitic dianhydride from their cut-off wavelengths (absorption edge, $\lambda_{0}$ ) in the optical absorption spectra. They found that the $\lambda_{0}$ is inversely correlated to the ionization potential (IP) of diamines and they attributed this mainly to the CTC formation. St. Clair et al., ${ }^{13,14}$ revealed that bulky electron withdrawing groups such as $-\mathrm{SO}_{2}-$ and $-\mathrm{C}\left(\mathrm{CF}_{3}\right)_{2}-$, flexibilizing groups such as $-\mathrm{O}-$, and meta-linked diamine structures lighten the color and increase the solubility. These phenomena were attributed to the reduction of the intermolecular CTC formation.

Although IP of diamines can be used as an indicator for the coloration of polyimides, the number of reported IPs are limited because of its experimental difficulty. There had been a strong demand for new indices of the electronic properties of aromatic diamines. We have revealed that the electron-donating properties of diamines can be quantitatively estimated by ${ }^{15} \mathrm{~N}$ NMR chemical shifts, and we have reported the orders of reactivity of acylation for a series of aromatic diamines. ${ }^{15}$ In this study, we discuss the relationships between the color intensities of polyimide films that could result from intra- and inter-molecular electronic interactions and the electron-donating and electronaccepting properties of their source materials: diamines and dianhydrides.

\section{EXPERIMENTAL}

\section{Materials}

Pyromellitic dianhydride (PMDA), 4,4'-oxydiphthalic dianhydride (ODPA), 3,3',4,4'-biphenyltetracarboxylic dianhydride (BPDA), and 3,3',4,4'-benzophenonetetracarboxylic dianhydride (BTDA) were purchased from Tokyo Kasei Kogyo Co., Ltd. 2,2-Bis(3,4-dicarboxyphenyl)hexafluoropropane dianhydride (6FDA) was obtained from Hoechst Japan Ltd. The methods of synthesizing fluorinated dianhydrides-1,4-difluoro2,3,5,6-benzenetetracarboxylic dianhydride (P2FDA), 1-trifluoromethyl-2,3,5,6-benzenetetracarboxylic dianhydride (P3FDA), 1,4-bis(trifluoromethyl)-2,3,5,6benzenetetracarboxylic dianhydride (P6FDA), 1,4bis(3,4-dicarboxytrifluorophenoxy)-tetrafluorobenzene dianhydride (10FEDA)-have been described elsewhere. ${ }^{8,16,17} 2,2^{\prime}$-Bis(trifluoromethyl)-4,4' -diaminobiphenyl (TFDB) and 2,2'-Bis(4(4-aminophenoxy)phenyl)hexafluoropropane were obtained from Central Glass Co., Ltd. Other diamines were purchased from Tokyo Kasei Kogyo Co., Ltd. All the dianhydrides and diamines were purified by sublimation under reduced pressure. The method of preparing poly(amic acid) solutions from various dianhydrides and TFDB diamine has been described elsewhere. ${ }^{6}$ The poly(amic acid)s dissolved in $N, N$-dimethylacetamide were spin-coated onto 3-inch silicon wafers. After the solvent was removed by drying at $70^{\circ} \mathrm{C}$ for $1 \mathrm{~h}$, the poly(amic acid) films were heated to $350^{\circ} \mathrm{C}$ (the final curing temperature) at $4^{\circ} \mathrm{C} \mathrm{min}^{-1}$ under nitrogen, kept at $350^{\circ} \mathrm{C}$ for $1 \mathrm{~h}$, and then cooled to room temperature. The thicknesses of the polyimide films peeled from substrates were $18 \pm 3 \mu \mathrm{m}$. The color intensities of the polyimides were estimated from the wavelengths of $50 \%$ transmission and their appearance.

NMR and Ultraviolet-Visible (UV-Vis) Measurements

High resolution ${ }^{13} \mathrm{C}$ and ${ }^{15} \mathrm{~N}$ NMR spectra were measured at 100.63 and $40.56 \mathrm{MHz}$ respectively with a Bruker MSL-400 spectrometer at room temperature $\left(22 \pm 2{ }^{\circ} \mathrm{C}\right)$. The distortionless enhancement of polarization transfer (DEPT) sequence was used for ${ }^{15} \mathrm{~N}$ NMR measurement, where the value of $85 \mathrm{~Hz}$ was used as a standard scalar coupling constant for $\mathrm{N}-\mathrm{H}$ bonds at amino groups. Samples were dissolved to a concentration of about $6 \mathrm{wt} \%$ in dimethyl-sulfoxide- $d_{6}$. The ${ }^{13} \mathrm{C}$ chemical shifts were calibrated from the internal tetramethylsilane (TMS), and the ${ }^{15} \mathrm{~N}$ chemical shifts were calibrated indirectly through the nitromethane signal (380.4 ppm from $\mathrm{NH}_{3}$ ).

UV-Vis absorption spectra of polyimide films were measured with a Hitachi U-3500 spectrophotometer at room temperature. Samples were dried at $110^{\circ} \mathrm{C}$ for 1 hour before the measurement to avoid the influence of moisture adsorbed on polyimide films.

\section{Calculation}

Electron affinities $\left(E A_{\text {cal }}\right)$ of dianhydrides were calculated using the MNDO-PM3 semi-empirical molecular orbital approximation. ${ }^{18}$ They can be estimated as the differences in total energy between the neutral molecule and their anion. The total energies of the anions were calculated under the uncoupled Hartree-Fock condition. The molecular geometries of molecules were fully optimized within the MNDO-PM3 framework. ${ }^{19}$ The optimized dihedral angles between two benzene rings for the dianhydrides consisting of two or three aromatic rings are as follows: $\left(46^{\circ}, 46^{\circ}\right)$ for $6 \mathrm{FDA},\left(51^{\circ}, 54^{\circ}\right)$ for BTDA, $49^{\circ}$ for BPDA, $\left(86^{\circ}, 3^{\circ}\right)$ for ODPA, $\left(5^{\circ}, 84^{\circ}\right)$ and $\left(80^{\circ}, 5^{\circ}\right)$ for $\mathrm{HQDEA},\left(76^{\circ}, 76^{\circ}\right)$ and $\left(76^{\circ}, 76^{\circ}\right)$ for 10FEDA.

\section{RESULTS AND DISCUSSION}

\section{Color Intensity of Polyimides and Electron-Donating Property of Diamines}

Structural formulae of the diamines arranged in order of ${ }^{15} \mathrm{~N}$ NMR chemical shift of amino nitrogen $\left(\delta_{\mathrm{N}}\right)$ are shown in Figure 2. Most of these $\delta_{\mathrm{N}}$ have been reported by the authors. ${ }^{20}$ Upfield chemical shift ( $\delta_{\mathrm{N}}$ is decreased, compound number is smaller) corresponds to the increase in electron-donating property of diamine, which should lead to a deep color in polyimides according to the CTC formation theory. Electron-releasing substituents $\left(-\mathrm{CH}_{2}-\right.$ and $\left.-\mathrm{O}_{-}\right)$displace $\delta_{\mathrm{N}}$ upfield, and electron-withdrawing substituents $\left(-\mathrm{CF}_{3}\right.$ and $\left.-\mathrm{SO}_{2}-\right)$ displace $\delta_{\mathrm{N}}$ downfield. These inductive effects are always stronger for ortho- (o-) and para- $(p-)$ substituted groups than for groups substituted at the meta- $(\mathrm{m}-)$ position. Thus the polyimide films from diamine 3 and 4 ( $p$ substituted) are expected to be more deeply colored than those from diamine 8 and 7 ( $m$-substituted). Although diamine 5 has a $p$-substituted electron-withdrawing $-\mathrm{C}\left(\mathrm{CF}_{3}\right)_{2}-$ group, the electron-releasing effect of the two $-\mathrm{O}-$ groups is stronger. The introduction of $-\mathrm{CF}_{3}$ groups and $-\mathrm{SO}_{2}-$ into the $m$-position from the amino groups also decreases the electron-donating property of 
<smiles>CCCNc1ccc(Oc2ccc(NCC)c([Se])c2)cc1</smiles><smiles>CCNc1ccc(Oc2ccc(C(C)(c3ccc(Oc4ccc(N)cc4)cc3)C(F)(F)F)cc2)cc1</smiles><smiles>CCCc1cccc(Cc2cccc(N)c2)c1</smiles><smiles>CC(C)(C)c1cccc(Oc2cccc(N)c2)c1</smiles>

63.9

65.7

Figure 2. Aromatic diamines arranged in order of amino group ${ }^{15} \mathrm{~N}$ NMR chemical shift $\left(\delta_{\mathrm{N}}\right)$. Smaller $\delta_{\mathrm{N}}$ corresponds to strong electron-donating property of diamine.

(a) Dianhydrides : PMDA, BPDA, ODPA, HQDEA (ref.6)

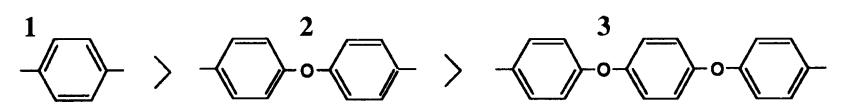

(b) Dianhydrides : 6FDA, ODPA (ref.10)

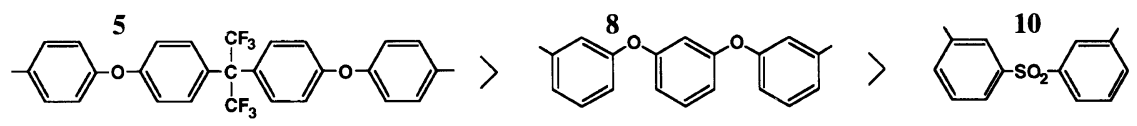

(c) Dianhydride : BTDA (ref.20)

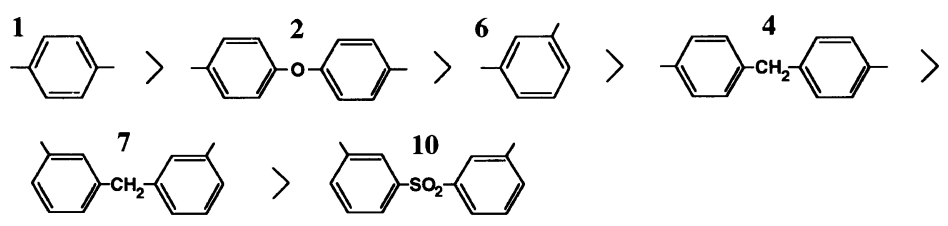

(d) Dianhydride : BPDA (ref.20)

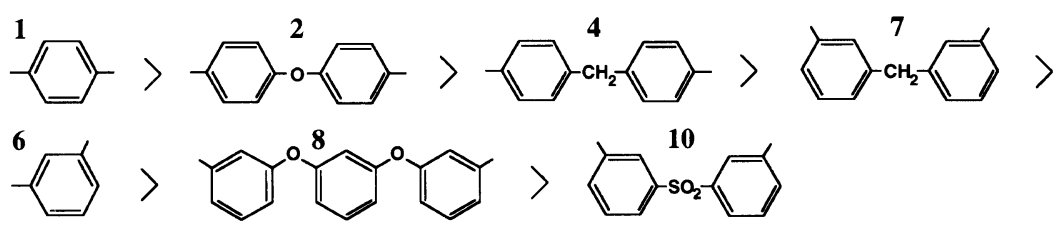

Figure 3. Diamine moieties arranged in order of color intensity of polyimide. Diamines located on the left side produce polyimide films with deeper colors.

diamine 9 and 10 .

Figure 3 shows arrangements of diamine moieties in order of the color intensity of polyimides from deep to pale when the dianhydride structures are fixed. These were prepared from the data reported by Bikson, ${ }^{9} \mathrm{St}$. Clair, ${ }^{13}$ and Noda. ${ }^{20}$ For the diamines shown in Figures 3(a) and (b), the color intensities of the polyimides were elucidated from the $\lambda_{0}$ observed in their absorption spectra. St. Clair et al. ${ }^{13}$ mentioned that $\lambda_{0}$ is directly related to the color intensity of polyimide films. On the other hand, the order of diamines shown in Figures 3(c) and (d) was estimated from their yellowness indices of the polyimides reported by Noda et al., ${ }^{20,21}$ who used this index as a measure of color intensity of polyimides. The order of the diamines estimated from the yellowness indices for the polyimides obtained from PMDA is not shown because it can be included in the orders of Figures 3 (c) and (d). Although the order of diamines 4 and 6 in Figure 3(c) and that of diamines 6 and 7 in Figure 3(d) are reversed, the order of color intensity of polyimides shows fairly good agreement with the order of $\delta_{\mathrm{N}}$ of diamines in Figure 2. This clearly indicates that, when the dianhydride structure is fixed, the coloration of polyimides is dominated by the electron-donating property of diamine, and that the electron-donating properties of diamines are retained to a significant extent 
(a) Experimental and calculated electron affinity<smiles>CCOC(=O)c1cc2c(cc1C(=O)OCC)C(=O)OC2=O</smiles><smiles>CCOC(=O)c1ccc2c(c1)C(=O)OC2=O</smiles><smiles>O=C1OC(=O)c2cc(-c3ccc4c(c3)C(=O)OC4=O)ccc21</smiles>

(2.49)<smiles>O=C1OC(=O)c2cc(Oc3ccc4c(c3)C(=O)OC4=O)ccc21</smiles>

(2.38)<smiles>CCOc1ccc(Oc2ccc3c(c2)C(=O)OC3=O)cc1Oc1ccc2c(c1)C(=O)OC2=O</smiles>

(2.05)

(b) ${ }^{13} \mathrm{C}$ chemical shift of carbonyl carbons

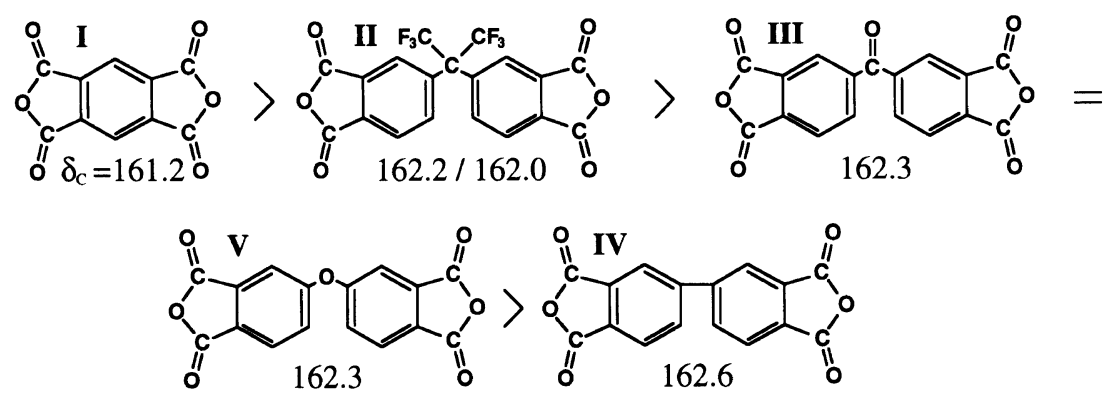

Figure 4. Aromatic dianhydrides arranged in order of experimentally measured electron affinity $(E A)$, calculated electron affinity $\left(E A_{\mathrm{cal}}\right)$, and carbonyl group ${ }^{13} \mathrm{C}$ NMR chemical shift $\left(\delta_{\mathrm{C}}\right)$. Larger $E A$ and smaller $\delta_{\mathrm{C}}$ correspond to the strong electron-accepting property of the dianhydride.

even in polyimide molecular chains. This observation also confirms that the color intensity of polyimides can be predicted from the ${ }^{15} \mathrm{~N}$ NMR chemical shift of diamines. The diamines that have small $\delta_{\mathrm{N}}$ should produce polyimides showing deeper colors. The reverse of the orders between color intensity and $\delta_{\mathrm{N}}$ stated above is related to the fact that the yellowness indices of diamines 4,6 , and 7 are very close to each other ${ }^{20}$ and their exact order is difficult to determine.

\section{Color Intensity of Polyimides and Electron-Accepting} Property of Conventional Dianhydrides

Figure 4 shows structural formulae of conventional dianhydrides arranged in order of experimentally measured electron affinity $(E A)$, calculated electron affinity $\left(E A_{\text {cal }}\right)$, and ${ }^{13} \mathrm{C}$ NMR chemical shift of carbonyl carbons $\left(\delta_{\mathrm{C}}\right)$. Some of $E A \mathrm{~s}$ and $\delta_{\mathrm{C}}$ have been reported by Pebalk et $a .^{22}$ and the authors. ${ }^{15}$ The $E A_{\text {cal }}$ is proportional to the $E A$ with a slope of 1.38 , where the correlation coefficient is 0.96 . The quantum chemical calculation of $E A$ well reproduce the orders of experimental values. A larger $E A$ (compound number is smaller in the figure), and an upfield chemical shift $\left(\delta_{\mathrm{C}}\right.$ is decreased) correspond to an increase in electronaccepting properties of dianhydrides, which has the same effect on the CTC formation as the strong electrondonating properties of diamines. This should lead to a deeper color in polyimide films.

Fluorine, the most electronegative element, should increase the electron-accepting properties of dianhydrides. However, the orders in Figure 4 show that the electron-accepting property of the fluorinated dianhydride, 6FDA is lower than that of PMDA. This results from that the quaternary carbon at the $-\mathrm{C}\left(\mathrm{CF}_{3}\right)_{2}-$

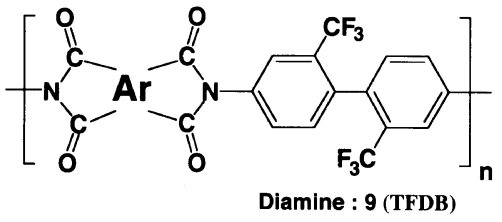

Figure 5. Structural formula of the polyimides synthesized from aromatic dianhydrides and a fluorinated diamine, TFDB.

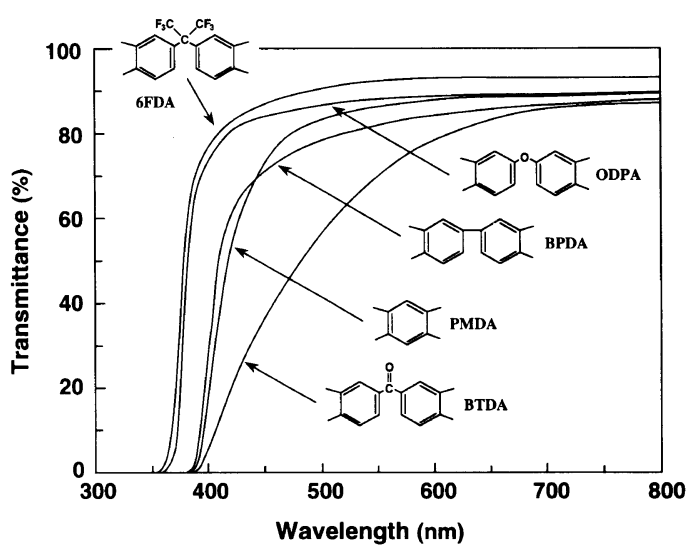

Figure 6. UV-Vis absorption spectra of the polyimide films prepared from five conventional dianhydrides and TFDB diamine.

group significantly prevents the transfer of the electronwithdrawing effect of $-\mathrm{CF}_{3}$ groups to the anhydride groups. Although 6FDA is the most popular fluorinated dianhydride, the quaternary carbon brings very unique properties for this dianhydride compared to the other fluorinated dianhydrides as described below.

Figure 5 shows a structural formula of the polyimides prepared in this study using a fluorinated diamine, TFDB. Figure 6 shows UV-Vis absorption spectra of the 
(a) Diamine : 9 (this study)

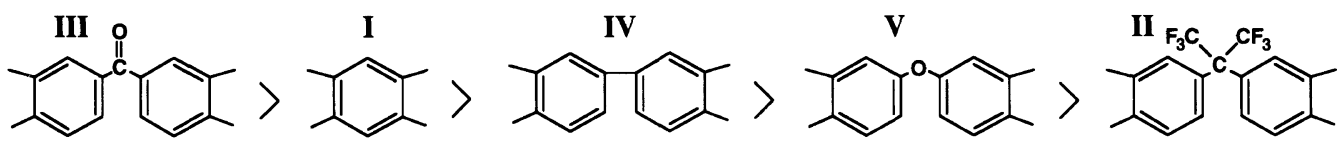

(b) Diamines : 1, 2, and 5 (ref.9)

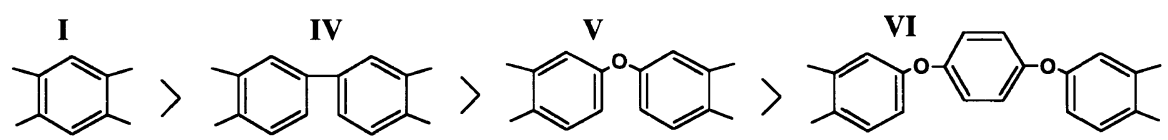

(c) Diamines : 4, 8, and 9 (ref.13)

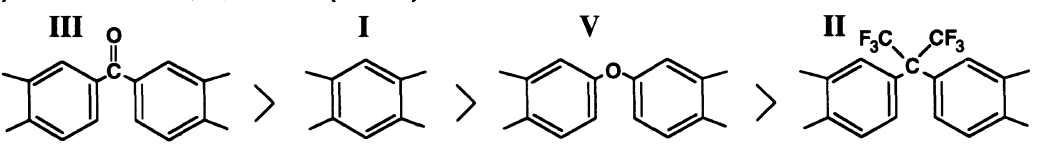

(d) Diamines : 3 and 10 (ref.20)

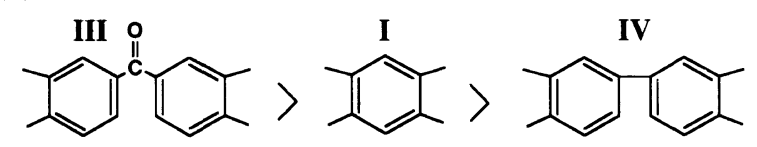

Figure 7. Dianhydride moieties arranged in order of color intensity of polyimide. Dianhydrides located on the left side produce polyimide films with deeper colors.

polyimides derived from TFDB and five kinds of conventional dianhydrides. The 6FDA and ODPA produce fairly transparent and almost colorless polyimide films in contrast to other dianhydrides. Although the polyimides derived from 6FDA and ODPA have the same $\lambda_{0}$, the former exhibits higher transparency at shorter wavelengths $(380-400 \mathrm{~nm})$ than the latter. On the other hand, BTDA/TFDB is brown and has low transparency in the visible region despite its $\lambda_{0}$ being close to those of PMDA/TFDB and BPDA/TFDB. The latter two polyimides are yellowish orange. As clearly seen in the spectra, the deep color of BTDA/TFDB is caused by the absorption curve trailing to longer wavelengths (about $650 \mathrm{~nm}$ ).

Figure 7 shows the arrangements of dianhydrides in order of color intensity of polyimides from deep to pale where the diamine structures were fixed. The diamines labeled with the compound numbers are shown in Figure 1. The orders of (a) was derived from the spectra in Figure 6, and those of (b), (c), and (d) are prepared from the data reported by Bikson, ${ }^{9}$ St. Clair, ${ }^{13}$ and Noda. ${ }^{20}$ It is noteworthy that there is no inconsistency in the orders of color intensity, and the polyimides derived from BTDA and 6FDA always have deeper and lighter colors, respectively, than those expected from their electron-accepting properties. Comparing the orders in Figure 4 and Figure 6, the arrangements in color intensity agree well with those of the electron-accepting properties of dianhydrides with the exception of BTDA and 6FDA.

The deep color of the polyimides prepared from BTDA can be explained by cross-linking reactions occurring at benzophenone $\mathrm{C}=\mathrm{O}$ groups. Pfeifer et al. ${ }^{23}$ reported that photo-imagable polyimides can be prepared from BTDA and diamines whose ortho-position with respect to amino groups was substituted with alkyl groups. Higuchi et al. ${ }^{24}$ have also revealed that an excited triplet state of benzophenone moiety extracts a hydrogen atom from an alkyl group of a neighboring polymer chain, resulting in ketyl and benzyl radicals, some of which cause a cross-linking reaction between polymer chains. At elevated temperatures of around $350^{\circ} \mathrm{C}$, a thermal cross-linking reaction is likely to take place even for the polyimides derived from diamines whose ortho-position was not substituted and BTDA. The cross-linked portion usually shows a deep yellow color because unsaturated double bonds are left after the reaction. Takekoshi ${ }^{25}$ pointed out that the formation of an imino group may take place between the carbonyl group in benzophenone moiety and the amino group at the end of the polymer chain. Aromatic imines are usually intense yellow.

On the other hand, the light colors of the polyimides having $-\mathrm{C}\left(\mathrm{CF}_{3}\right)_{2}-$ groups in their dianhydride moieties can be explained from the decreased intermolecular interactions. We have recently reported that the intermolecular packing coefficients of polyimides are considerably decreased by introducing $-\mathrm{CF}_{3}$ groups from the comparison of the observed and the calculated refractive indices. ${ }^{26}$ St. Clair ${ }^{13}$ stated that the bulk $-\mathrm{CF}_{3}$ group in $6 \mathrm{FDA}$ is effective in preventing the CTC formation between polymer chains through steric hindrance. The low polarizability of fluorine and fluorinated groups also weakens the intermolecular interactions. The decrease of intermolecular CTC formation is understandable also from the significant solubility of the polyimides prepared with 6FDA.

Although the orders of electron-accepting property between BPDA and ODPA estimated from $E A$ and $\delta_{\mathrm{C}}$ are reversed in Figures 4(a) and (b), the polyimides derived from BPDA are always more deeply colored than those from ODPA as shown in Figures 7(a) and (d). This indicates that $E A$ is a better index than $\delta_{\mathrm{C}}$ for predicting the color intensity of the polyimides derived from conventional dianhydrides.

Color Intensity of Polyimides and Electron-Accepting Property of Perfluorinated and Partially Fluorinated Dianhydrides

Figure 8 shows structural formulae of perfluorinated 
(a) Calculated electron affinity
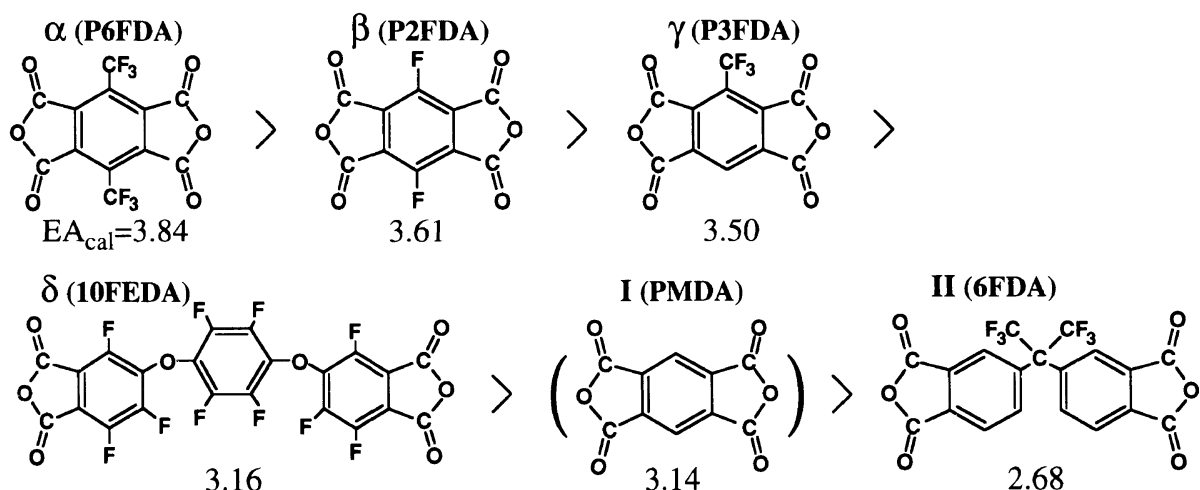

(b) ${ }^{13} \mathrm{C}$ chemical shift of carbonyl carbons

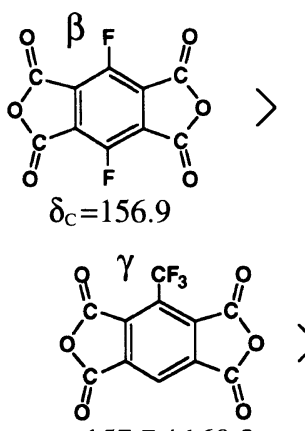

$157.7 / 160.2$<smiles>O=C1OC(=O)c2c(F)c(Oc3c(F)c(F)c(Oc4c(F)c(F)c5c(c4F)C(=O)OC5=O)c(F)c3F)c(F)c(F)c21</smiles>

157.5<smiles>O=C1CC(=O)c2c1c(C(F)(F)F)c1c(c2C(F)(F)F)C(=O)OC1=O</smiles>

157.6

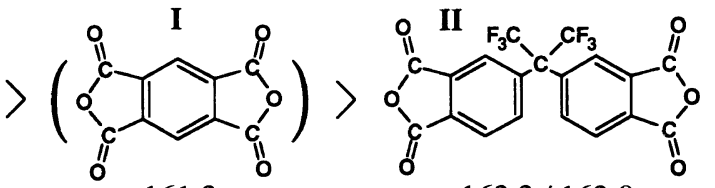

161.2

$162.2 / 162.0$

Figure 8. Fluorinated aromatic dianhydrides arranged in order of calculated electron affinity $\left(E A_{\text {cal }}\right)$ and carbonyl group ${ }^{13} \mathrm{C}$ NMR chemical shift $\left(\delta_{\mathrm{C}}\right)$. Larger $E A_{\text {cal }}$ and smaller $\delta_{\mathrm{C}}$ correspond to the strong electron-accepting property of the dianhydride.

and partially fluorinated dianhydrides arranged in order of $E A_{\text {cal }}$ and $\delta_{\mathrm{C}}$. The perfluorinated dianhydrides -P6FDA, P2FDA, and 10FEDA - are the source materials for the perfluorinated polyimides. ${ }^{8,17}$ As stated above, fluorines should increase the electron-accepting properties of dianhydrides. It is certain that the three perfluorinated dianhydrides and P3FDA have larger $E A_{\text {cal }}$ than the conventional dianhydrides. This indicates that the electron-accepting properties of the former dianhydrides are stronger than those of the latter ones, resulting from the direct influence of electron-withdrawing $-\mathrm{F}$ and $-\mathrm{CF}_{3}$ groups. According to the CTC formation theory, these highly fluorinated dianhydrides should lead to deeper colors in polyimides than the conventional dianhydrides. The inconsistency of the orders estimated from $E A_{\text {cal }}$ and $\delta_{\mathrm{C}}$ in Figures 8(a) and (b) can be explained from the steric effect that occurs in the dianhydrides having $-\mathrm{CF}_{3}$ groups adjacent to the anhydride groups, P3FDA and P6FDA. The electronaccepting properties estimated from the $\delta_{\mathrm{C}}$ for the dianhydrides are considerably weaker than those estimated from $E A_{\text {cal }}$. The $\delta_{\mathrm{C}}$ of P3FDA and P6FDA should be displaced downfield by the steric hindrance between their $-\mathrm{CF}_{3}$ and carbonyl groups. On the other hand, $E A$ is relatively insensitive to such the steric effect. This suggests that $E A_{\text {cal }}$ is a better index for estimating the electron-accepting property of highly fluorinated dianhydrides than $\delta_{\mathrm{C}}$, as before.

Figure 9 shows UV-Vis absorption spectra of the polyimide films prepared from the five kinds of dianhydrides and one fluorinated diamine, TFDB. All the polyimides have deeper colors (dark brown to burnt umber) than PMDA/TFDB which is included for

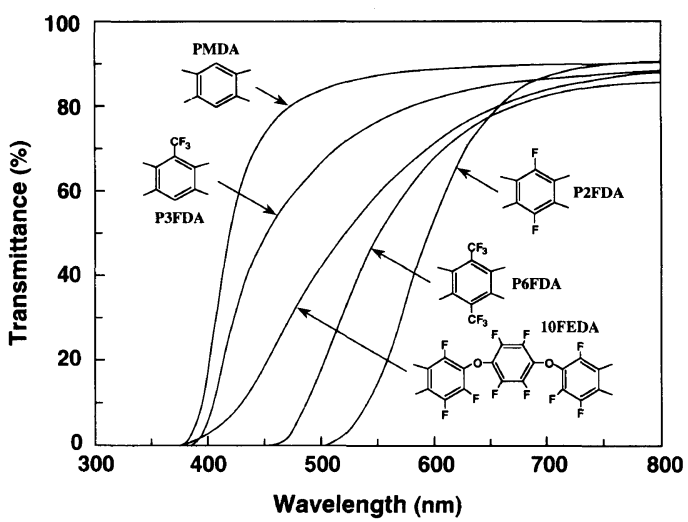

Figure 9. UV-Vis absorption spectra of the polyimide films prepared from the fluorinated dianhydrides and TFDB diamine. The spectrum of PMDA/TFDB is included for comparison.

comparison. This is consistent with the strong electronaccepting property of these highly fluorinated dianhydrides. As clearly shown in the spectra, $\lambda_{0}$ is not directly related to the color intensity of the polyimides. In particular, 10FEDA/TFDB has low transparency and a dark brown color although its $\lambda_{0}$ is close to that of P3FDA/TFDB, which is pale orange. The deep color observed for 10FEDA/TFDB is obviously caused by the absorption curve trailing to longer wavelengths (400 to $800 \mathrm{~nm}$ ). This phenomenon is similar to that of BTDA/ TFDB in Figure 6, where the occurrence of cross-linking reaction is suspected. De Pasquale et al. ${ }^{27}$ have reported that the reaction of $\mathrm{C}_{6} \mathrm{~F}_{5} \mathrm{O}^{-} \mathrm{Na}^{+}$and $\mathrm{C}_{6} \mathrm{~F}_{5} \mathrm{CN}$ in DMAc at $60^{\circ}$ affords polysubstituted products. If the main chain of $10 \mathrm{FEDA} / \mathrm{TFDB}$ is severed and $\mathrm{C}_{6} \mathrm{~F}_{5} \mathrm{O}^{-}$ ion is generated at the dianhydride moiety under the 
(a) Color intensity<smiles>[B]c1c(C)c(C)c(C)c(C(C)C)c1CCC</smiles>

(b) Cut-off wavelength: $\lambda_{0}$

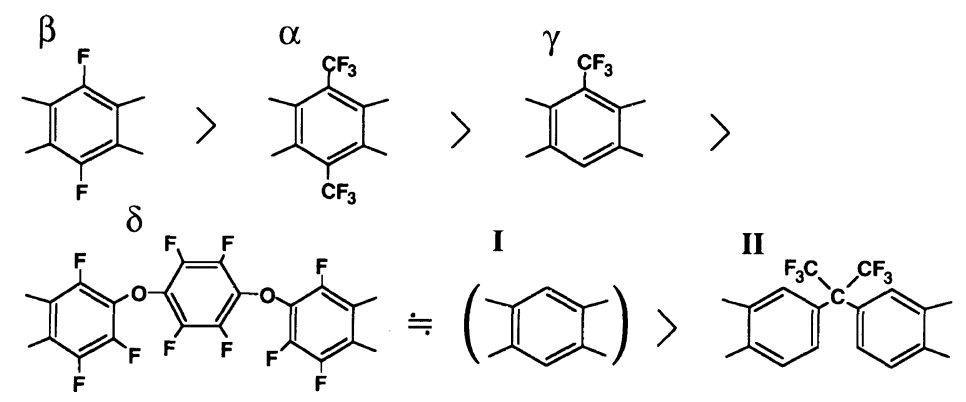

Figure 10. Perfluorinated and partially fluorinated dianhydride moieties arranged in order of color intensity of polyimides and their cut-off wavelengths.

$350^{\circ} \mathrm{C}$ curing, polysubstitution or cross-linking reactions are likely to occur because fluorines directly bonded to benzene rings are very electronegative similarly to cyano group.

Figure 10 shows the arrangement of the dianhydrides in order of the color intensity of polyimides and the $\lambda_{0}$ derived from the spectra in Figure 9. The order in terms of $\lambda_{0}$, which should be closely related to the degree of CTC formation, agrees with the electron-accepting properties estimated from $E A_{\text {cal }}$ with the exception of P2FDA. P2FDA/TFDB polyimide has the deepest color and the longest $\lambda_{0}$ among the six dianhydrides, although its $E A_{\text {cal }}$ is smaller that of P6FDA. The lighter color of P6FDA/TFDB compared to P2FDA/TFDB can be explained by the steric effect of two $-\mathrm{CF}_{3}$ groups, which should be effective in preventing CTC formation between polymer chains. This is the same phenomena seen in the 6FDA-based polyimides. In addition, the planar structure of P2FDA is very suitable for the intermolecular packing and the intermolecular CTC formation. This is the reason that P2FDA produced the deepest color polyimide films in this study. The fact that all the polyimides derived from highly fluorinated dianhydrides, except for 6FDA, have deep colors is consistent with the CTC formation theory. We can say that the fluorination of source materials does not necessarily lead to colorless polyimides.

\section{CONCLUSIONS}

The arrangement of the diamine moieties in order of color intensity of polyimides show fairly good agreement with that of the electron-donating properties of the diamines estimated from their amino group ${ }^{15} \mathrm{~N}$ NMR chemical shifts. This clearly indicates that the coloration of polyimides is dominated by the electron-donating property of diamine when the dianhydride structure is fixed. On the other hand, some systematic inconsistencies were observed between the arrangement of the dianhydride moieties in order of color intensity and the electron-accepting properties of the dianhydrides estimated from the electron affinities and their carbonyl group ${ }^{13} \mathrm{C}$ NMR chemical shifts. The polyimides obtained from BTDA and 6FDA show systematically deeper and lighter colors than those expected from their electron-accepting property. The former is due to the cross-linking reaction occurred at benzophenone $\mathrm{C}=\mathrm{O}$ groups, and the latter is due to the decreased intermolecular CTC formation caused by the bulky and weakly polarizable-C $\left(\mathrm{CF}_{3}\right)_{2}$-group. The reverse of the coloration observed for the polyimides derived from P2FDA and P6FDA can be explained by the increased and decreased intermolecular CTC formation, originating from the planar structure of the former and the two $-\mathrm{CF}_{3}$ groups of the latter. For the other dianhydrides, their electron-accepting properties are reflected in the coloration of polyimides. Hence, it can be concluded that the electron-donating properties of diamines and electron-accepting properties of dianhydrides are retained to a significant extent even in polyimide molecular chains, and the coloration of polyimides can be inferred from the ${ }^{15} \mathrm{~N}$ NMR chemical shift of diamines and the electron affinity of dianhydrides.

\section{REFERENCES}

1. B. S. Dupont and N. Bilow, U.S. Patent, 4,592,925 (1986) and A. L. Landis and A. B. Naselow, U.S. Patent, 4,645,824 (1987).

2. For example, K. Higashi, and Y. Noda, Eur. Patent, 240249 (1986) and S. Tamai, M. Ohta, S. Kawashima, H. Oikawa, K. Ohkoshi, and A. Yamaguchi, Eur. Patent, 234882 (1987).

3. T. Matsuura, S. Ando, S. Sasaki, and F. Yamamoto, Electron. Lett., 29, 2107 (1993). 
4. S. Ando, T. Sawada, and Y. Inoue, Electron. Lett., 29, 2143 (1993).

5. F. E. Rogers, U.S. Patent 3,356,648 (1964)

6. T. Matsuura, Y. Hasuda, S. Nishi, and N. Yamada, Macromolecules, 24, 5001 (1991).

7. S. Ando, T. Matsuura, and S. Sasaki, Macromolecules, 25, 5858 (1992).

8. S. Ando, T. Matsuura, and S. Sasaki, ACS Symp. Ser., No. 537, The American Chemical Society, Washington D.C., 1994, pp $304-322$.

9. B. R. Bikson and Y. F. Freimanis Vysokomol Soyedin., Ser., A, 12, 69 (1970).

10. R. A. Dinc-Hart, and W. W. Wright, Makromol. Chem., 143, 189 (1971).

11. R. S. Mulliken, J. Am. Chem. Soc., 74, 811 (1952).

12. B. V. Kotov, T. A. Gordina, V. S. Voishchcv, O. V. Kolninov, and A. N. Pravednikov, Vysokomol. Soyedin., Ser., A, 19, 614 (1977).

13. A. K. St. Clair and T. I. St. Clair, Am. Chem. Soc. Div. Polym. Mater. Sci. Eng., 51, 62 (1984).

14. A. K. St. Clair, T. L. St. Clair, W. S. Slemp, and K. S. Ezzell., "Proceedings of the 2nd International Conference on Polyimides," Ellenville, N.Y., 1985, p 333.

15. S. Ando, T. Matsuura, and S. Sasaki, J. Polym. Sci., Part A, 30
2285 (1992).

16. T. Matsuura, M. Ishizawa, Y. Hasuda, and S. Nishi, Macromolecules, 25, 3540 (1992).

17. S. Sasaki and T. Matsuura, Polym. Prepr. Jpn., 40, 829 (1991).

18. M. J. S. Dcwar and W. Thiel, J. Am. Chem. Soc., 99, 4899 (1977).

19. MOPAC Ver. 6.0, J. J. P. Stewart, QCPE \#455, QCPE Bull., 9, 10 (1989).

20. Y. Noda and T. Nakajima, Polym. Prepr. Jpn., 35, 1245 (1986).

21. Japanese Industrial Standard JIS-K7103, "Testing Methods for Yellowness Index and Change of Yellowness Index of Plastics," Japanese Industrial Standards Committee, Tokyo (1977).

22. D. V. Pebalk, B. V. Kotov, O. Y. Nejland, I. V. Mazcrc, V. Z. Tilika, and A. N. Pravednikov, Dokl. Akad. Nauk. S.S.S.R., 236, 1379 (1977).

23. J. Pfeifer and O. Rhode, "Recent Advances in Polyimide Science and Technology," The Society of Plastic Engineers, Poughkepsie, New York, 1987, p 336

24. H. Higuchi, T. Yamashita, K. Horie, and I. Mita, Chem. Materials, 3, 188 (1991).

25. T. Takekoshi, Adv. Polym. Chem., 94, 1 (1990)

26. S. Ando, Kobunshi-Ronbunshu, 51, 251 (1994).

27. R. J. De Pasquale and C. Tamborski, J. Org. Chem., 33, 1658 (1968). 